\title{
La cooperación en el desarrollo de la Humanidad: de los hechos históricos a la tenacidad de la axiología cooperativa en los pilares de la sostenibilidad
}

\author{
José Eduardo de Miranda
}

Sumario: I. Consideraciones preliminares: el preludio de la acción cooperativa. Il. Cuando el Hombre se hace Hombre: el despertar (in)consciente de la sostenibilidad. III. La evolución del Hombre sostenida por valores propios de la cooperación: la solidificación del que hacer cooperativo. IV. Las nuevas tendencias del progreso y la preservación de la confianza en el trabajo cooperativo. V. Rochadle: un entorno debilitado socio y económicamente que determinó el punto de partida de las cooperativas modernas como efectivo mecanismo de transformación del hombre. VI. A título de reflexión final: el hombre en el mundo hoy y el sustrato axiológico de la cooperación como presupuesto de sostenibilidad. VII. Referencias bibliográficas.

Resumen: Aunque se conozca la historia del Cooperativismo, se va a exhibir la presencia de la cooperación, en cuanto valor, en el proceso de desarrollo de la humanidad. Asimismo, presentase las primeras técnicas co-operativas, desarrolladas bajo valores propios de respecto con el medio y con el común, permitiendo al hombre sustraer de la naturaleza los medios indispensables a su supervivencia. También, se va a demostrar la importancia de la cooperación como mecanismo de superación de necesidades socio-económicas, y, sobretodo, la importancia del sustrato axiológico de la cooperación como presupuesto de sostenibilidad.

Palabras clave: cooperación, desarrollo, sostenibilidad.

Abstract: Although he is known the history of the cooperative movement, it will display the presence of cooperation, in how much value in the process of development of mankind. Also, submit the first co-operative, developed techniques under eigenvalues of respect with the environment and with the common, allowing the man to subtract from the nature the essential means to their survival. Also, is going to demonstrate the importance of cooperation as a mechanism for overcoming socio-economic needs, and, above all, the importance of the axiological substrate of cooperation as a sustainability budget.

Key words: cooperation, development, sustainability.

1 Doctor en Derecho; Abogado Parecerista; Director General de la Facultad de José Bonifácio-SP/BR. 


\section{Consideraciones preliminares: el preludio de la acción cooperativa}

Los registros históricos presentan datos sobre las técnicas de fabricación de herramientas, prácticas sociales más o menos diferenciadas y rasgos físicos relacionados a los diferentes cambios evolutivos de la especie humana ${ }^{2}$. Respeto a la prehistoria de la cooperación, las crónicas demuestran que esta fase no ha sido objeto de un análisis profundo ${ }^{3}$, pues los datos existentes resultan de las sucintas referencias que diferentes autores han realizado para identificar las primitivas características del sistema cooperativo ${ }^{4}$.

No obstante, es importante decir que durante la prehistoria el hombre se agrupa en tribus, hordas o bandas. Las más variadas actividades son desarrolladas en común, a través de la cooperación de grupos dedicados a tareas específicas. Así es como, también, las estructuras organizadas corresponden a colectividades formadas para ofrecer resistencias en las guerras de unos contra otros, las comunidades aldeanas utilizan los medios de producción de propiedad comúny obtienen los bienes necesarios para el consumo del mismo grupo humano.

Asimismo sus miembros trabajan conjuntamente bajo la dirección de un jefe elegido por ellos mismos ${ }^{5}$, pero el conjunto se forma libre de cualquier espíritu de ventaja de unos miembros sobre los demás ${ }^{6}$. El grupo se compone en pro de la congregación, y cada cual aplica todas sus fuerzas para el alcance de un provecho único, que es de todos, independientemente del grado de fuerza aplicado por uno o por otro.

Teniendo en cuenta esta realidad, el presente trabajo sostiene el rescate del contexto histórico de la cooperación y su importancia en el proceso de desarrollo de la humanidad, presentando la axiología del cooperativismo como el pilar de realización del Hombre, delante del Hombre y del mundo.

2 WarbasSE, J.P. Democracia cooperativa. Buenos Aires: Editorial Americalee, 1956. p. 17

3 Mladenatz, G. Historia de las doctrinas cooperativas. Buenos Aires: Intercoop, 1969. p. 11.

4 SOldeVILLA Y VILlAR, A.D. El movimiento cooperativista mundial. Valladolid: Talleres Gráficos Ceres, 1973. p. 6.

5 Kaplan de Drimer, A. \& Drimer, B. Las cooperativas. Fundamentos-historia-doctrina, Buenos Aires: Intercoop Editora Cooperativa Limitada, 1981, pp. 195 y 196.

6 Homans, G. The human group. New Cork: Brace and Company, 1950, p. 141. 


\section{Cuando el Hombre se hace Hombre: el despertar (in)consciente de la sostenibilidad}

Los fósiles que día tras día son hallados por los investigadores de la paleontología y los estudios de la antropología demuestran que en el curso evolutivo de la Humanidad, desde mucho antes de que apareciese el Homo sapiens, han existido incontables especies en el camino de la humanización, pero la única que ha sobrevivido ha sido la que mejor se ha adaptado al medio ambiente y mejor supo utilizar la naturaleza en su provecho. Aunque los orígenes de la Humanidad sean de difícil precisión, se admite, por lo general, que el antepasado del hombre empieza a diferenciarse de los simios, sus parientes más cercanos, hace entre 5 y 6 millones de años ${ }^{7}$.

Al estar aislado en el interior de la sabana seca, al este de África, tuvo que adaptarse, a diferencia de los simios que vivían en los árboles de la selva ecuatorial, a un medio diferente y modificar su estilo de vida. También por aquel entonces sufre unos cambios decisivos en la anatomía de las caderas y de los pies ${ }^{8}$.

De un modo general, estos cambios corporales le facilitan al homínido el contacto con el medio natural: postura erecta, dentición con los caninos atrofiados, capacidad craniana más grande que los demás primates. Sin embargo, estas transformaciones no representan datos que ofrezcan conclusiones precisas sobre un u otro tema relacionado con el Hombre en sí mismo.

Todos los procesos metamorfósicos trascienden en el fenómeno de la hominización, y demuestran que la ocurrencia de una evolución física ha generado una estructura morfológica sin cualquier medio específico de ataque, defensa o evasión. Es decir, la evolución de la especie humana no es el reflejo de una específica adaptación, si no que significa el supremo sentido de adaptación general, a cualquier medio.

Diferente de los demás animales que han habitado su espacio natural, el Hombre no ha poseído garras para atacar presas, no ha tenido caninos afilados para destrozar sus cazas, nunca jamás tuvo la destreza de una liebre o avestruz para huir de sus perseguidores, y tampoco sus pelos han sido suficientemente gruesos para protegerlo del frío.

Es así que el Hombre siempre ha tenido un equipamiento corporal inferior al de las otras especies, y tuvo que buscar mecanismos de su-

7 LARROUSSE. Los orígenes de la civilización. Madrid: Larousse-RBA, 1996, p. 13.

8 Ibid., p. 13.

9 Aquino, R. Historia das sociedades: das comunidades primitivas às sociedades medievais. Rio de Janeiro: AO Livro Técnico S/A, 1984, p. 50. 
presión de las necesidades: ha sido así para acabar con el hambre, con el frío y con el peligro ${ }^{10}$.

Con todo, el Hombre ha descubierto que a pesar de su disminuida estructura física, la naturaleza le ha brindado con un sistema nervioso desarrollado que le permite una gran variedad y precisión de movimientos que se ajustan a los impulsos recibidos de los órganos delicados de sus sentidos. Es justo en este momento, cuando descubre su capacidad de armonizar el movimiento de sus diversos órganos de acuerdo a la percepción de los sentidos y de los nervios motores, que el Hombre consigue controlar los movimientos de sus muslos y logra ajustar sus reacciones a las diferencias del entorno que le cerca. Sobre ello, Ostrower instruye que el desarrollo del sistema nervioso ha permitido un gran potencial de sensibilidad, pero la sensibilidad es un estado de excitabilidad sensorial que representa una puerta abierta a las sensaciones. Es decir, la sensibilidad representa una «abertura constante al mundo y nos enchufa de modo inmediato a todo que ocurre a nuestro alrededor» ${ }^{11}$.

Ha sido en el instante en que el Hombre tuvo la sensibilidad que le permite examinar el medio en donde vive y buscar del entorno la mejora de sus condiciones de vida, cuando nuestra especie llega al apogeo de su proceso evolutivo y se muestra diferente de las demás especies de animales que ocupan sus respectivos espacios en el Planeta ${ }^{12}$.

Más débil físicamente que muchos de los demás seres vivos, tiene el Hombre una gran capacidad de adaptación a cualquier cambio y es dotado de la habilidad para la construcción de herramientas adecuadas para enfrentar las circunstancias del medio en que vive. El Hombre desarrolla una intima relación con el medio, pero de ello solamente sustrae lo que hace falta para su supervivencia.

Se tiene, entonces, el marco de unos 1,5 millones de años desde el aparecimiento de la especie más evolucionada que sale de África y llega a conquistar el mundo. Esta especie, parecida al hombre actual en configuración, peso y capacidad craneana, produce utensilios y utiliza el fuego. De otra forma, hace 40.000 años el Homo sapiens sapiens completa la colonización del mundo llegando a Australia y a América atravesando el estrecho de Bering. A este hombre que habla, entierra sus muertos y toma conciencia del tiempo, sólo le falta cultivar la tierra,

\footnotetext{
10 Ostrower, F. Criatividade e processos de criação. Petrópolis: Vozes, 1978, p. 11.

11 Ibid., p. 12.

12 Aquino, 1984, p. 52.
} 
domesticar los animales y construir ciudades, para parecerse al hombre actual ${ }^{13}$.

Durante este período el Hombre actúa sobre la naturaleza y de ella sustrae la materia prima necesaria a la producción de bienes que necesita para enfrentar los cambios naturales. Por ello, el Hombre desarrolla la conciencia de si mismo y del medio. Descubre la importancia del espacio en donde habita y atribuye un efectivo valor a la existencia social, pues su actuación sobre la naturaleza deja de ser en solitario y se opera a través de la colaboración de sus iguales ${ }^{14}$.

\section{La evolución del Hombre sostenida por valores propios de la cooperación: la solidificación del que hacer cooperativo}

Vencida la época en que su antepasado se las ha ingeniado para reproducir el fuego, desarrollar la agricultura, inventar el lenguaje o descubrir la cerámica, el hombre ingresa en la Edad Antigua. En esta fase, las actividades económicas han sido establecidas en base a la esclavitud, de modo que las organizaciones libres no pudieron ser desarrolladas ${ }^{15}$.

No obstante, los rasgos co-operativos constatados en la antigüedad han sido los propios de relaciones interpersonales desarrolladas para obtener la ayuda mutua necesaria para afrontar las dificultades de supervivencia. En la época anterior al nacimiento de Jesucristo, también hemos observado la preservación de la naturaleza gregaria del hombre, pues la historia nos ha revelado que la cooperación permite que pueblos de diferentes regiones puedan satisfacer a las necesidades variadas ${ }^{16}$.

Asimismo, se advierte que en el Israel bíblico, bajo el reinado de Salomón, la cooperación deja vestigios muy precisos, cuando se encuentran las primeras huellas cooperativos, ya que, "al permitir a las familias patriarcales realizar ciertas funciones de asistencia, a las que tenían derecho a beneficiarse todos los que formaban parte de la pequeña sociedad familiar, desde la cabeza de la familia o jefe, hasta el humilde siervo o esclavo, no se hacía otra cosa que fomentar la cooperación» ${ }^{17}$.

13 LARROUSSE, 1996, p. 13.

14 Rivera Campos, J. El secreto de Rochadle. Buenos Aires: Intercoop Editora Cooperativa Limitada, 1973, p. 11.

15 Kaplan de Drimer, A. y Drimer, B. Manual de cooperativas. Buenos Aires: Intercoop Editora Cooperativa Limitada, 1977, p. 42.

16 PAlACIO, A. Cooperativismo. Zaragoza: La Editorial. pp. 9 y 10.

17 Cerdá Richart, B. Doctrina e historia de la cooperación. Barcelona: Bosch, 1959. p. 137. 
También se afirma que los ágapes de los primeros cristianos, y las sociedades de pequeños artesanos griegos y romanos constituían una expresión de cooperativas que han funcionado rigurosamente sobre la base de ayuda mutua ${ }^{18}$.

De este modo, resulta evidente que al principio de los tiempos la convivencia humana se establece en grupos muy rudimentarios y como consecuencia del afecto entre los seres opuestos se llega a la familia ${ }^{19}$ y de ahí al clan, la tribu, la horda y otras formas primitivas, luego al revolucionar las necesidades y surgir los fenómenos sociales, aparecen los gremios, los municipios y los Estados y en otros órdenes de la vida social, las asociaciones culturales, religiosas, políticas, benéficas, deportivas, etc., en que se diluye toda la actividad humana de fraternización.

Es decir, desde sus orígenes, el Hombre busca en el grupo la mejor manera para asegurar su realización personal, la defensa de su integridad física, la satisfacción de necesidades indispensables para la subsistencia.

Para ello renuncia a ciertas ventajas personales en nombre del valor que permite la agregación de unos con los otros; un valor sin estimación económica, pero que le permite al Hombre observar que las acciones humanas en la búsqueda del bien son absolutamente supremas, y no tienen precio.

Antes de que apareciese el valor económico, las actitudes, el afecto, la simpatía y el auto-sacrificio desempeñan una parte inmensa, pero no exclusiva en el desarrollo progresivo de nuestros sentimientos morales. Es decir, no es el afecto, ni siquiera la simpatía los que constituyen pilares sobre los que se apoya la humanidad.

El verdadero pilar de sostén es la conciencia de la solidaridad humana y la autoayuda, aunque sea en la etapa del instinto. Según Preuss, es «el reconocimiento inconsciente de la fuerza que cada hombre toma prestado de la práctica de la ayuda mutua; de la estrecha dependencia entre la felicidad de cada uno y la felicidad de todos; y del sentido de la justicia y equidad lo que conduce al individuo a considerar los derechos de todos los demás individuos, como iguales a sus principios» 20 .

18 SOLDEVILLA Y VILLAR, 1973, p. 2.

19 WARBASSE, 1956, p. 22.

20 Preuss, W. El cooperativismo en Israel y en el mundo. Tel-Aviv: Centro de Estudios Cooperativos y Laborales, 1966, p. 31. 


\section{Las nuevas tendencias del progreso y la preservación de la confianza en el trabajo cooperativo}

Una fase más inmediata para el estudio de los antecedentes de la cooperación ha de empezar necesariamente en los inicios de la Edad Media $^{21}$. Este periodo, que comprende desde el siglo $V$ hasta el siglo $\mathrm{xV}$, ha venido marcado por guerras, invasiones territoriales y formación de nuevos Estados.

De esta época se conservan relatos de las crisis de hambre, tan horrorosas que no se comprende cómo la humanidad ha podido sobrevivir. Estos siglos han sido de miseria extrema, en los que el noventa y cinco por ciento de la población no tiene más ropa que la que lleva puesta22.

La escasez del dinero, la miseria de los pueblos y el surgimiento del concepto gremial de sociedad artesana, va uniendo a los comerciantes, pequeños industriales, artesanos y hasta hombres de la tierra, en un indiscutible movimiento que enciende la llamada solidaridad humana y registra trazos incuestionablemente cooperativos. Se han conocido sociedades de agricultores, agrupaciones de artesanos, comerciantes y de cristianos.

Como ejemplo, podemos citar que en Francia, se constituyen en el siglo XII O XIII las frutières, que conservan esta denominación hasta nuestros días y constituyen queserías cooperativas; en las regiones del Jura y de Saboya, la fabricación común de quesos se impone por motivos técnicos, debido a que los quesos Gruyère allí elaborados tienen gran tamaño y requieren la producción lechera de un considerable número de explotaciones; los quesos producidos se dividen en tales casos entre los campesinos en proporción al número de sus animales y se distribuye, en igual proporción, el dinero proveniente de la venta de los productos que exceden las necesidades de consumo de los mismos campesinos ${ }^{23}$.

En los Alpes franceses y suizos, donde el ganado de los valles era y es aún llevado a pastos de verano, lejos del comprador de leche líquida, ha sido costumbre, cuando menos desde la Edad Media, hacer queso; ya que en el queso de buena calidad debe hacerse en volumen y con leche que tenga pocas horas de ordeña, este queso se hace a diario con la leche mezclada de todas las vacas de la aldea. Más tarde, en el otoño, cuando los quesos ya sazonados están listos para su venta,

21 Divar, J. La alternativa cooperativa: una respuesta ante la crisis. Barcelona: Ceac, 1985, p. 17.

22 Rivera CAMPOS, 1973, p. 15.

23 Kaplan de Drimer, A. y Drimer, B., 1981, p. 197. 
se divide el producto o su importe entre los aldeanos, en proporción al número de vacas que posee cada uno.

Digby subraya que «no se conocen en forma tan clara, ejemplos antiguos de cooperación urbana, aunque en las grandes ciudades de las épocas griega y romana había sociedades de entierro y de seguro mutuo, y muchos gremios de trabajadores, incluyendo los artels rusos que subsisten hasta la época moderna, se parecían más a las sociedades cooperativas de productores que a los sindicatos modernos.

Todo esto, sin embargo, es nada más para decir que la asociación en el trabajo, así como en la diversión, es natural en el hombre, y que, en una etapa muy primitiva, la ayuda mutua se había extendido más allá del grupo familiar y que había adquirido una forma organizada y bastante permanente» ${ }^{24}$.

En los medios urbanos, el ritmo de las nuevas condiciones socioeconómicas concentra el crecimiento de la población en las ciudades, donde las clases medias, representadas por artesanos y comerciantes, se organizan en guildas o corporaciones revestidas de rasgos semejantes a los que revisten los sindicatos y cooperativas de nuestra época.

Además de representar a los respectivos grupos de artesanos y comerciantes ante las autoridades, las guildas desarrollan importantes actividades de ayuda entre sus miembros sobre una base de hermandad, arbitran en sus conflictos internos y, en algunos casos, realizan tareas de venta de los productos en común y compra en conjunto de las materias primas requeridas ${ }^{25}$.

Asimismo, no se puede olvidar que la cooperación ha estado presente en la historia del continente americano, principalmente en las civilizaciones Azteca, Inca y Maya, las cuales han desarrollado la forma de trabajo conjunto para la construcción de mecanismos de irrigación, de defensa u obras de carácter religioso.

En México han existido los «calpulli» o «calpullalli», constituidos en base a las tierras adjudicadas por los aztecas a los barrios o comunidades, para división en lotes o concesión en usufructo a las distintas familias, que solían unirse para realizar obras de irrigación y para otros objetivos comunes.

Ya, en Perú, los Inca han asignado anualmente a cada comunidad o "ayllu», en usufructo, la extensión de tierra que le correspondía según el número de sus miembros. El producto de las cosechas ha sido utilizado en común para el pagamiento de los tributos; el resto se re-

24 DigBY, M. El movimiento cooperativo mundial. México D.F.: Centro Regional de Ayuda Técnica-Agencia para el desarrollo Internacional, 1965, pp. 15 y 16.

25 Kaplan de Drimer, A. y Drimer, B., 1981, p. 199. 
partía entre los jefes de familia, en proporción al número de personas a su cargo ${ }^{26}$.

Lo cierto es que en todos los puntos del Globo el hombre, por inclinación de su naturaleza, busca su pleno desarrollo no sólo en el ejercicio de sus facultades intelectuales, sino también en las raíces económicas en el espacio vital necesario para absorber con seguridad el jugo que alimenta.

Almarcha anota que «el hombre obtiene su pleno desarrollo cuando sus actividades tienen las raíces en espacio vital propio, o sea por objetos de propiedad propia» ${ }^{27}$. Es decir, «el ansia del hombre no se aquieta, como en el mundo animal y vegetal, por la satisfacción de la necesidad del momento, sino que además de la satisfacción de esta necesidad quiere, como ser inteligente, «la seguridad posible de que sus necesidades y las de su familia serán también satisfechas a través del tiempo con bienes en pleno dominio, de los cuales pueda usar y a los cuales pueda hacer producir el jugo que nutre, sin más limitación que la de la ley y sin más intervención que su voluntad» 28 .

\section{Rochadle: un entorno debilitado socio y económicamente que determinó el punto de partida de las cooperativas modernas como efectivo mecanismo de transformación del hombre}

Rochdale, un pequeño pueblo inglés del condado de Lancashire, representa el punto de partida de las cooperativas modernas ${ }^{29}$, pues de allí surge sus humildes fundadores que tanto se han mostrado capaces de emplear los frutos de la experiencia pasada, como también de seleccionar y sistematizar las normas fundamentales que adoptan desde entonces las cooperativas.

Todo empieza en el año de 1843, época en que el comercio de la franela pasa por una situación próspera y genera una actividad muy grande en Rochdale. No obstante, los trabajadores tejedores eran mal retribuidos y sus gestiones dirigidas a conseguir mejoras no obtienen resultado ${ }^{30}$.

26 Kaplan de Drimer, A. y Drimer, B., 1977, p. 42.

27 Almarcha, L. La cooperación como sistema económico-social. Madrid: Obra Sindical de Cooperación, 1945, p. 12.

28 Ibid., p. 12.

29 RICCICARDI, L. Cooperativismo: uma solução para os problemas atuais. Vitória: Sescoop, 2000, p. 26; GAWLAK, A. y RATZKE, F.A. Cooperativismo: filosofia de vida para um mundo melhor. 2. ed, Curitiba: Ocees, 2001, pp. 18 y 19; PALACIO, 1945, p. 22.

30 PALACIO, 1945, p. 23. 
Esta situación, de insatisfacción de los trabajadores, provoca que los tejedores organicen una reunión para debatir la cuestión y buscar una fórmula que les permita superar las dificultades existentes, ante la imposibilidad de obtener un aumento de sus salarios ${ }^{31}$. A esta reunión comparecen veintiocho obreros tejedores que intentan encontrar medios para mejorar su situación.

Diversas han sido las soluciones propuestas: algunos, recomiendan emigrar hacia otras zonas más propicias; otros, aconsejan la abstinencia en el consumo de bebidas alcohólicas para aumentar los recursos familiares; los cartistas se mostraron partidarios de la acción política para conseguir la sanción de la Carta Pueblo, que consagraría el sufragio universal y con él la posibilidad de que los trabajadores influyeran en la obtención de leyes protectoras ${ }^{32}$.

Por fin, y sin desechar las soluciones anteriores, triunfa la proposición de organizar, con recursos propios, un almacén cooperativo regido por normas establecidas por ellos mismos, y creado para proveer a sus socios mercaderías de buena calidad a precios justos y cuya utilidades, después de cubiertos ciertos destinos de carácter colectivo o social, fueran distribuidas en proporción al consumo 3334 .

Después de establecer la participación individual de cada socio, con un capital de una libra esterlina, reúnen la suma de veintiocho libras 35 utilizada el 24 de octubre de 1844 para registrar la Rochdale Equitable Pioneers Societ, la sociedad constituida para el fin de realizar un beneficio pecuniario y mejorar la condición doméstica de sus miembros ${ }^{36}$, a través de la ejecución del siguiente plan ${ }^{37}$ :

- Abrir una tienda para la venta de alimentos, ropa, etc.

- Comprar o construir casas para los socios que deseen ayudarse mutuamente para mejorar las condiciones de su vida doméstica y social.

- Emprender la fabricación de aquellos artículos que la sociedad considere convenientes para ofrecer trabajo a los miembros que

31 Jacobs Holyoake, G. Historia de los pioneros de Rochadle. Buenos Aires: Federación Argentina de Cooperativas de Consumo, 1944, p. 81.

32 Kaplan de Drimer, A. y Drimer, B., 1981, p. 228.

33 Kesselman, 1979, p. 26.

34 DesRoche, H. El desarrollo intercooperativo. Sus modelos y sus combinaciones. Buenos Aires: Intercoop Editora Cooperativa Limitada, 1977.

35 Mladenatz, 1969, pp. 66 y 67.

36 Watkins, W.P. Pensamiento estático y dinámico en el movimiento cooperativo. Buenos Aires: Intercoop Editora Cooperativa Limitada, 1973, p. 88.

37 BöÖKE, A. Valores cooperativos num mundo de mudanza. Lisboa: Instituto Antonio Sérgio do Sector Cooperativo-Inscoop, 1993, p. 56. 
se encuentren sin ocupación o que sufran a causa de repetidas reducciones en sus salarios.

- Comprar o arrendar tierras para ser cultivadas por sus socios desocupados o por aquellos insuficientemente pagados.

- En cuanto sea posible, la sociedad procederá a organizar la producción, la distribución y la educación en su seno y por sus propios medios; en una palabra, ella se constituirá en colonia autónoma en la que todos los intereses serán solidarios. La sociedad acudirá en ayuda de las otras sociedades cooperativas que desearen fundar colonias semejantes.

- A fin de propagar la solidaridad, la sociedad abrirá un establecimiento de templanza en una de las casas de la sociedad, tan pronto resultase conveniente ${ }^{38}$.

Por diez libras anuales alquilan el piso bajo de una casa, en una calle que por su aspecto responde a su nombre: Toad Lane. Es así que al anochecer del 21 de diciembre de 1844, día gris y frío, se abre la tienda con provisiones que se reducen a un poco de manteca, azúcar, harina y avena. Después de su apertura la cooperativa opera con horario reducido y solo durante dos días por semana ${ }^{39}$.

Hasta 1848 los años han sido de crisis y extremada miseria. Sin embargo, la cooperativa sigue creciendo, demostrando que puede afrontar cualquier borrasca. El local resulta pequeño y alquilan la totalidad de las tres plantas del edificio y una buhardilla 40 .

Desde su origen, la Cooperativa de Rochdale es una cooperativa de consumo, pero tal es su trascendencia en el momento histórico en que surge, su repercusión social y económica y su fundamento en la idea de asociación humana que se gestiona en aquellos tiempos, que se la considera como la raíz y base de toda clase de cooperativas, incluso las de producción y las de crédito ${ }^{41}$.

Probablemente los Probos Pioneros de Rochdale no se han percatado de la importancia y de la significación de su empresa ${ }^{42}$. Ellos inician el primer experimento cooperativo con la sola idea de proveer a sus familiares y al consumidor en general de bienes de consumo. Su

38 GaRIBALDI, A.J. Cooperativas y cooperativismo. Buenos Aires: Intercoop, 1965, p. 47.

39 Repetto, N. Lecciones sobre cooperación. Buenos Aires: Federación Argentina de Cooperativas de Consumo, 1944, p. 26.

40 Rivera Campos, 1973, p. 26.

41 SOldeVILLA Y VILLAR, 1973, p. 21.

42 Ibid., p. 22. 
ejemplo ha sido seguido después por millones de cooperadores de todos los países del mundo.

\section{A título de reflexión final: el hombre en el mundo hoy y el sustrato axiológico de la cooperación como presupuesto de sostenibilidad}

Para el hombre, en general, la calidad de su vida está condicionada al grado de su riqueza, de su liquidez económica y de sus posibilidades materiales...

Mientras se encuentre en condiciones de agrandar los valores de su cuenta en el banco y pueda materializar los objetos de sus deseos, el hombre es feliz: está feliz. Sin embargo, la felicidad, considerada a partir de la realización económica y de la satisfacción material, se muestra efémera, principalmente si es alcanzada en desprecio de la actitud del hombre en relación al medio ambiente natural.

Así, es necesario observar que la relación hombre versus medio ambiente es idesignio de futuro y significado de vida!

Por ello, actualmente, el término sostenibilidad se muestra protagonista en el guión de todos aquellos que sujetan banderas de defensa ambiental. Hablase del desarrollo sostenible como una actuación común, intrínseca a no afectación de la naturaleza. Aleccionase la interrelación de la sostenibilidad con el establecimiento de políticas públicas y acciones jurídicas de fiscalización y sanción por el inadecuado uso de los recursos naturales.

Este es el camino de la insostenibilidad...

Derivado del Relatorio Brundtland, editado en el año de 1987 por la Comisión Mundial respeto al Medio Ambiente y Desarrollo, de la Asamblea de las Naciones Unidas, la expresión desarrollo sostenible supone la idea del desarrollo que garantiza las necesidades de las generaciones presentes, sin la afectación de las capacidades de las generaciones futuras garantizar las suyas propias.

Ocurre que a partir de la asociación de la noción del desarrollo sostenible con la optimización de los medios adecuados a la satisfacción de las necesidades humanas presentes y futuras, se está a constituir un principio de responsabilidad que asocia las acciones de hoy con los efectos del mañana. De este modo, para la evidencia de un efectivo desarrollo sostenible, de acuerdo con la previsión del Relatorio Brundtland, es necesario hallarse un punto de equilibrio entre el crecimiento económico, la equidad sociopolítica y la protección del medio ambiente natural. 
La buena calidad del mañana está condicionada a la interacción del humano con los hechos relacionados al desarrollo. Es necesario que el hombre se posicione delante de los diferentes problemas que existen en el contexto donde se encuentra inserido, $y$, en la medida en que proyecte la mejora de sus condiciones de vida, constituya una forma de actuar propia al establecimiento de una postura ecológicamente correcta, económicamente viable, socialmente justa y culturalmente admitida.

El desarrollo sostenible depende de una efectiva transformación del hombre; de la prominencia de valores sostenibles; de la sostenibilidad moral.

Entonces, el desarrollo sostenible se consumará solamente cuando el hombre reconozca su importancia delante del medio, la importancia del medio en donde habita, y, por supuesto, entienda la importancia de aquellos que dividen el medio con él.

De la misma manera que ha ocurrido en los albores de la historia, también hoy la consciencia por el valor del colectivo, por la importancia del todo, ha de subrayar la fuerza de la actuación cooperativa como fenómeno social-solidario, intrínseco a la vida en comunidad.

Es, solamente sobre la trilla del espíritu cooperativo, que refleja los valores cooperativos editados por la Declaración de la Identidad Cooperativa de la Alianza Cooperativa Internacional, en el Congreso de Manchester, en 1995, que el hombre verá su capacidad de consolidar posturas adecuadas al desarrollo sostenible.

Antes de la fuerza de las leyes, más allá de la eficacia de la actuación de los órganos públicos de fiscalización y control, y con mucho más tenacidad que las sanciones administrativas o jurídicas, el desarrollo esencialmente sostenible se muestra posible cuando el hombre comprender y practicar los valores cooperativos fundamentales (ayuda mutua, autorresponsabilidad, democracia, igualdad, equidad y solidaridad) y éticos (honestidad, transparencia, responsabilidad y vocación social).

Al prevalecer los valores cooperativos como guía de su existencia, el hombre logrará rescatar el horizonte histórico que le ha estampado las posibilidades concretas de construcción de una sociedad justa e igualitaria, basada en principios de transformación indispensables a la afirmación de una nueva postura delante del medio natural, indispensables a la utilización racional de la naturaleza, con respecto a sus potencialidades, sin devastación de sus recursos. 


\section{Referencias bibliográficas}

AlmarCha, L. La cooperación como sistema económico-social. Madrid: Obra Sindical de Cooperación, 1945.

Aquino, R. Historia das sociedades: das comunidades primitivas às sociedades medievais. Rio de Janeiro: AO Livro Técnico S/A, 1984.

BöÖKE, A. Valores cooperativos num mundo de mudanza. Lisboa: Instituto Antonio Sérgio do Sector Cooperativo-Inscoop, 1993.

CERDÁ RICHART, B. Doctrina e historia de la cooperación. Barcelona: Bosch, 1959.

DESROCHE, H. El desarrollo intercooperativo. Sus modelos y sus combinaciones. Buenos Aires: Intercoop Editora Cooperativa Limitada, 1977.

DIGBY, M. El movimiento cooperativo mundial. México D.F.: Centro Regional de Ayuda Técnica-Agencia para el desarrollo Internacional, 1965.

DIVAR, J. La alternativa cooperativa: una respuesta ante la crisis. Barcelona: Ceac, 1985.

GARIBALDI, A.J. Cooperativas y cooperativismo. Buenos Aires: Intercoop, 1965.

Homans, G. The human group. New Cork: Brace and Company, 1950.

Jacobs Holyoake, G. Historia de los pioneros de Rochadle. Buenos Aires: Federación Argentina de Cooperativas de Consumo, 1944.

Kaplan De Drimer, A. \& Drimer, B. Las cooperativas. Fundamentos-historia-doctrina, Buenos Aires: Intercoop Editora Cooperativa Limitada, 1981.

- Manual de cooperativas. Buenos Aires: Intercoop Editora Cooperativa Limitada, 1977.

LARROUSSE. Los orígenes de la civilización. Madrid: Larousse-RBA, 1996.

Mladenatz, G. Historia de las doctrinas cooperativas. Buenos Aires: Intercoop, 1969.

Ostrower, F. Criatividade e processos de criação. Petrópolis: Vozes, 1978.

PALACIO, A. Cooperativismo. Zaragoza: La Editorial.

Preuss, W. El cooperativismo en Israel y en el mundo. Tel-Aviv: Centro de Estudios Cooperativos y Laborales, 1966.

RepetTo, N. Lecciones sobre cooperación. Buenos Aires: Federación Argentina de Cooperativas de Consumo, 1944.

RICCICARDI, L. Cooperativismo: uma solução para os problemas atuais. Vitória: Sescoop, 2000.

Rivera Campos, J. El secreto de Rochadle. Buenos Aires: Intercoop Editora Cooperativa Limitada, 1973.

SOLDEVILLA Y VILLAR, A.D. El movimiento cooperativista mundial. Valladolid: Talleres Gráficos Ceres, 1973.

WARBASSE, J.P. Democracia cooperativa. Buenos Aires: Editorial Americalee, 1956.

WatKINS, W.P. Pensamiento estático y dinámico en el movimiento cooperativo. Buenos Aires: Intercoop Editora Cooperativa Limitada, 1973. 